\title{
Application of Traditional Culture in Creation of Chinese Painting
}

\author{
Pengxian Huang \\ Hebei Academy of Fine Arts, Xinle Hebei, 050700, China
}

Keywords: Traditional culture, Chinese painting, Creation

\begin{abstract}
A large number of splendid traditional cultures were generated in the long historical development course of China. We are proud of the ceramic works, silk products and traditional Chinese paintings which are high-level artworks. However, under the fierce impact of current tide of reform as well as the socialist market economy with Chinese characteristics, the traditions left by our ancestors are gradually vanishing, so applying the essence of traditional culture in Chinese painting cannot be delayed even a moment. This paper elaborates the basic characteristics of Chinese painting, analyzes the necessity of introducing traditional culture in creation of Chinese painting, interprets the interrelationship between Chinese painting and "Dao" in traditional Chinese culture, and proposes the development prospect of creation of Chinese painting based on traditional culture.
\end{abstract}

\section{Introduction}

The excellent traditional culture of China has nourished the Chinese painting, Chinese operas and a large quantity of artistic forms with distinct national aesthetic characteristics. Due to its extremely long development history, the creation of Chinese painting has a unique style after being combined with the calligraphy, seal and other Chinese traditional artistic forms. The artistic form of Chinese painting originates in the matrix of Chinese culture, so all the formal skills of malapropism, moss etc. and the spiritual idea of unity between nature and human etc. can reflect the special aesthetic interest in Chinese traditional culture. The author hereby tries to deeply explore the essence of traditional culture based on creation of Chinese painting so as to make a little contribution to the development of Chinese painting art in the future.

\section{Basic characteristics of Chinese painting}

After development for thousands of years and making continuous efforts by painters in all ages, Chinese painting, which is born in China and is a unique drawing form of China, has its unique painting style and artistic charm and has distinct characteristics in the global drawing system due to its diversified patterns of manifestation. The basic characteristic of Chinese painting is the way of creation by using ink and lines. Apart from ink and lines, other ways of manifestation such as color-painting, the ethereal and distant space-time feeling, the wonderful images excelling nature and the flexible composition of a picture etc. are all the main ways of manifestation of the artistry of Chinese painting. Meanwhile, the painter's expression is especially reflected in the landscape painting, bird-and-flower painting and figure painting, so much attention is paid to the mutual coherence and connection of "Qi" as well as the turn of "Shi" in composition arrangement, application of lines in a painting and changes in color and ink drafting in a painting; thus, the vigor with a unique rhythm, charm and flexicity can be formed in the painting to further embody the vitality and lasting appeal of Chinese painting. In addition, the seal and inscription on a Chinese painting comprehensively enrich the content and charm on a painting and thus add an all-important brushstroke to the peculiar formal beauty in Chinese painting.

\section{Necessity of introducing traditional culture in the creation of Chinese painting}

Compared with the western plastic arts, the creation training of Chinese painting pays more attention to how to inherit the traditional culture and how to inherit the patterns of drawing. Therefore, the western painting pays more attention to the paint from life while the creation of Chinese painting 
pays more attention to imitation. In the development of Chinese painting, the there almost have been no big changes in picture showing like the creation of western painting. The style of Chinese painting and the style in the context of western painting have always been different. The extreme pursuit for style, which is emphasized in Chinese painting, largely exceeds the emphasis on painting realistically. The eastern and western countries are greatly different in the cognition of beauty. Just as Huang Binhong, a well-known painter, said: when learning Chinese painting, one should simulate the paintings of Yuan Dynasty first due to the excellent techniques of using brushes and ink; next, one should simulate the paintings of Ming dynasty due to the smooth and steady structure; later, one should simulate the paintings of Tang dynasty to achieve learning back from the ancient times; finally, one should simulate the paintings in Song dynasty due to the constant changes. In consideration of this, it is the most meaningful to analyze the creation of contemporary painting in the environment of traditional culture. The thinking of only stressing the artistic conception without pursuing the similarity in shape pervades the whole painting, so mechanical revivification of nature is not deliberately required. From the perspective of some layers, the scholar-officials having the right to criticize arts also accept this opinion, so those who only focus on the superficial painting are considered to be short of artistic characteristic; due to the natural instincts of romance, Chinese people intentional belittle the so-called diabolic tricks and wicked craft but concern more the expression of interest and charm. Because of the extremely profound influence of this thought, the Chinese painting maters still tenaciously pursue the elegant painting style even when they are expressing the heaviness of the ruined country and starving people as well as the depression of unrealized aspiration. As far as the theory of painting art, the artistic expressive force and aesthetic attitude can construct the tradition of Chinese art. However, based on the theory of focusing on the representation, the functions of painting skills are neglected. It is required to be point out that Chinese paint can promote the further formalization of Chinese arts so that their representation can reach a new peak. However, the art of Chinese painting can be said to be a relatively premature artistic form. After the North Song dynasty, especially the traditional landscape painting characterized by the prominence of blue and green colors started to vanish and the Chinese painting creators began to lose interest in colors, resulting in the prematurely starting the metaphysical artistic conception .

\section{Interrelationship between Chinese painting and "Dao" in traditional Chinese culture}

The greatest achievement in Chinese traditional painting is to profoundly reveal the essence of the universe. Both the calligraphy works and painting works can reflect the global appearance through a small aspect; we can say that the universe can be perceived through a very small aspect. The Chinese painting art, which integrates with the poem, calligraphy, painting, seal and other artistic forms in Chinese traditional culture, is a comprehensive artistic form. In addition, it has been nourished by the traditional culture of Chinese ethnic peoples for five thousand years, so it has a very close relationship with "Dao", the center of Chinese traditional culture. The Chinese painting, especially the painting of man-of-letters, is deeply influenced by "Dao" with only the difference in periods and influence conditions. Before learning Chinese painting, a painter should understand "Dao" first. If not, the painter may only learn the representation of painting without deeply understanding the quintessence of painting. The essence of creation of Chinese painting art lies in expressing one's individual feeling in the artistic form so as to determine the personalized essence of a painting. The Chinese traditional Taoist school perceived the world with the thinking against the law and their theory perceived attentively provided a better angle for painters to recognize themselves and to show the world. It is exactly this spirit which laid a non-rational ideological foundation for the creation art of Chinese painting. On this basis, the painters further broke through the limit of shapes, colors and space-time concepts and realized the artistic freedom and thought liberation. In this way, painters can do the creation with facility, reveal the artistic conception without focusing on the shapes, and reach the realm of coherent creation.

Much attention is paid to the painting principle in Chinese painting. That the principle mentioned here actually has a subordination relationship with the aforesaid "Dao" can be clearly reflected and verified in Chinese traditional painting. For instance, the principle of composition in Chinese painting 
stresses the combination of virtuality and reality; the principle of modeling focus on conveying the spirit with forms; the principle of writing focuses on the disuse of Chinese ink dividing into five colors as well as the continuous handwriting potential without cut strokes; the principle of overall creation focuses on learning from nature. The painting principles above are completely different from other artistic types but all particularly embody the spirit of "Dao". However, it is needed to realize both common principles and non-common principles in Chinese painting. The painting principle can be said to be the unity of variability and invariability. One can deeply grasp the quintessence of painting principle in Chinese painting only when one soberly realizes this. Similarly, the technique of Chinese painting also has an extremely close relationship with "Dao". Compared with the metaphysical characteristic of painting principle, the expression characteristic of painting technique is within the shape, because the painting technique is visible and can be simulated with various skills. The Chinese painting is most particular about the techniques which specifically include the drawing, method of the use of ink and water, art of composition, portraying method etc. But the Chinese painting also pays attention to the disuse of techniques which means not sticking to the specific painting techniques. Only in this way, the wonderful artistic conception in a painting can be revealed and this is the fundamental of Chinese painting art.

\section{Development prospect of creation of Chinese painting based on traditional culture}

Firstly, combine the traditional culture with the innovation thought. In the development history of Chinese painting for thousands of years, the Chinese painting underwent the incomparable glory and decline phases. The historical experience warned us that it is required to adhere to the principle that adversity leads to changes and changes lead to innovations so as to the full-strength innovation by making the past serve the present if we want to make sustainable development in Chinese painting. It is required to dialectically analyze the tradition and innovation based on the principles of Chinese painting. That is to say, there are common and non-common principles in the painting, so we should not only pursue innovation in tradition but also learn to preserve the tradition in innovation. To inherit the Chinese traditional culture, we should commit ourselves to controlling the attitude of seeking quick success and instance interest. One needs to learn how to behave before learning how to create painting works and should not only imitate the ancients' painting but also learn their attitude. Absorption and inheritance aim at better development while development aims at better absorption and inheritance. Therefore, for both development and inheritance, one must stick to the principle that the central theme remains the same and profoundly realize that Chinese painting is a new painting art with its own system created by Chinese ethnic peoples through accumulation and precipitation for thousands of years. To make the Chinese painting truly integrate into the current era, the step-by-step principle must be used during modification or innovation. The true integration can generally be realized only after unremitting efforts made by several generations.

Secondly, combine the quintessence of oriental art with the advantages of western art. When viewing Chinese painting, a large number of researchers use the modern painting view emerging after the "May 4th Movement" to treat the tradition of Chinese painting school with a long history. After a long time, they will habitually neglect the practical communication issues in Chinese and western cultures behind the traditional issues of Chinese painting. For instance, once the tradition of Chinese painting is mentioned, the contemporary people will intentionally compare with the western oil painting; once the culture reform is mentioned, they will presumingly explore a way out from the western culture rather than seek the ideal answers from Chinese traditional culture. Actually, it seems that some western cultures run in the opposite direction of Chinese culture on the face, but the quintessence in both of them has something in common. One should fully understand both the Chinese painting and oil painting like a beginner by exceeding the so-called conventions determined by the predecessors so that one should not be influenced by the first concepts. This is the so-called "not use of specific techniques prevailing over the use of techniques" It means that one thoroughly empties all kinds of knowledge stored, treats the various differences between Chinese and western cultures with the most real attitude, and absorbs the quintessence. 
Thirdly, improve the college entrance exam records of culture subject of college students majoring in Fine Arts as far as possible. To better integrate the traditional culture into the creation of Chinese painting art, it is required to practically change the way of enrolling art students in the college entrance exam and try to enhance the proportion of cultural academic results. Although all kinds of art colleges pay more and more attention to the academic records, it is true that the art college students' academic records are low when they enter colleges. To make the art college students, who may get engaged in professional creation of Chinese painting in the future, to have good traditional culture foundation, it is required to enhance their academic records from the beginning, practically control the cultural basic quality of student resources enrolled, and should put the academic records in the same important position of art records based on evaluating their specialized art course records. Only in this way, can we fundamentally guarantee that the specialized art talents conveyed to institutions of higher learning have good professional qualities and the qualities of traditional culture. This can also help the students to further deepen their understanding of traditional culture in the college stage.

Fourthly, absorb the quintessence and discard the dregs of traditional culture. We must well identify the traditional culture. Since everything in the world has its two sides, we cannot absolutely and blindly accept all of it. After the "May $4^{\text {th }}$ Movement", numerous Chinese painting works blindly imitated, accepted and rejected the traditional culture and failed to practically absorb the quintessence and discard the dregs. This one-sidedness result in the extreme of some Chinese painting works. Besides, such works don't have the artistic quality of traditional art but excessively rely on the western culture. This goes against the inheritance of Chinese traditional culture and further causes the huge loss of Chinese traditional cultural elements. From the perspective of artistic effect, the teaching mode of slavishly copying will cause Chinese painting to lose the vitality and thus will go against the final presentation of the visual effects of Chinese painting.

Fifthly, practically increase the mutual combination of all different disciplines. Honestly, most of our classical Chinese painting works integrate with abundant cultural connotations. The Chinese traditional culture revealed in such works not only is limited to the traditional knowledge of Chinese painting but also covers the fine artistic works with a strong cultural ambience contained by the great family of whole Chinese nationalities including the mural, carving, New Year picture, paper-cut and traditional opera etc. Thus, in the course of creation of Chinese painting, full combination of different types of traditional cultural and artistic forms can largely expand the horizon of Chinese art culture and better show the great, profound and rich connotation of Chinese painting.

\section{Conclusion}

To sum up, the core of traditional culture is the philosophic consciousness, namely, the organic combination of ideal aesthetic awareness and actual state and both the development and innovation of creation art of Chinese painting must be rooted in the abundant soil of traditional culture. As for our attitude towards traditional culture, we need to reasonably sublate some of traditional culture in the process of inheritance and should also inherit the traditional culture in the process of sublation. The author firmly believes that we can make our contributions to the Chinese painting industry as long as we continuously insist on deep exploration as well as tenacious and audacious innovation.

\section{References}

[1] Chen Ruilin. Artistic Appreciation of Chinese Painting. Taiyuan: Shanxi Education Press, 1997.

[2] Wang Nanmin. Art Must Die. Shanghai: Shanghai Painting and Calligraphy Press, 2006.

[3] Pei Shenli. Brief Discussion about Chinese Painting Education for Teenagers. Henan Vocation-Technical Teachers College, 2008 (4).

[4] Yang Lili. Some Reflections on the Lack of Traditional Culture in Creation of Chinese Painting. Artistic Forum, 2011 (29) 